Check for updates

Cite this: RSC Adv., 2017, 7, 36735

Received 23rd January 2017

Accepted 12th July 2017

DOI: $10.1039 / \mathrm{c} 7 \mathrm{ra00953d}$

rsc.li/rsc-advances

\section{Electrochemical properties of a silicon nanoparticle/hollow graphite fiber/carbon coating composite as an anode for lithium-ion batteries}

\begin{abstract}
Liyong Wang, (DD ab Zhanjun Liu, ${ }^{\text {*a }}$ Quangui Guo, ${ }^{a}$ Xiaohui Guo and Jianjun Gu${ }^{b}$
Herein, a double strategy to modify the cycling performance of pure silicon nanoparticles (SiPs) was applied. Hollow graphite fibers (HGFs) with a good graphite structure could improve the electrical conductivity of the electrode. The SiP/HGF composite maintained a discharge capacity of $556.2 \mathrm{~mA} \mathrm{~h} \mathrm{~g} \mathrm{~g}^{-1}$ and a charge capacity of $548.6 \mathrm{~mA} \mathrm{~h} \mathrm{~g}^{-1}$ after 50 cycles at the current density of $50 \mathrm{~mA} \mathrm{~g}^{-1}$, which obviously promoted the lifetime as compared to that of the anode of pure SiPs. Carbon coating could minimize the direct contact between the SiPs and electrolyte and buffer the volume changes during cycling. The silicon nanoparticle/hollow graphite fiber/carbon-coated (SiP/HGF/C) composite delivered the initial discharge and charge capacities of 1327.2 and $936.6 \mathrm{~mA} \mathrm{~h} \mathrm{~g}$, respectively, at a current density of 50 $\mathrm{mA} \mathrm{g}^{-1}$. After the first cycle, the charge capacity began to steadily increase to $1122.7 \mathrm{~mA} \mathrm{~h} \mathrm{~g}^{-1}$ until the thirty-first cycle. The double strategy effectively buffered the volume changes, enhanced the intensity of the electrode, and improved the overall electrical conductivity during discharge-charge cycles. The lowcost SiP/HGF/C composite showed an optimized electrochemical performance as compared to the pure SiP anode.
\end{abstract}

\section{Introduction}

With the rapid increase in global energy consumption, the exhaustion of fossil fuels, and increase in environmental problems, energy storage and conversion has become a key issue affecting our daily life. ${ }^{\mathbf{1}-3}$ Rechargeable lithium-ion batteries (LIBs), named by Sony Corp., can store and release electric energy many times and are promising for green energy applications. Carbon materials were first adopted as anode materials for commercialized LIBs, providing safety during application. ${ }^{4}$ To date, a number of carbon materials have been investigated ${ }^{5}$ such as graphite, ${ }^{6-8}$ amorphous carbon, ${ }^{9,10}$ carbon fibers ${ }^{11-15}$ carbon nanotubes, ${ }^{16-23}$ and graphene. ${ }^{\text {24-33 }}$

Graphite electrodes were exfoliated in propylene carbonatebased electrolytes; this resulted in drastic decomposition of the electrolyte and thus led to large irreversible capacity. Spherical natural graphite with a carbon coating not only avoids direct contact with the electrolyte, but also achieves excellent electrochemical performance. Spherical carbon-coated natural graphite exhibits a reversible capacity of $360 \mathrm{~mA} \mathrm{~h} \mathrm{~g}^{-1}$, and its most coulombic efficiencies are over $90 \% .^{34}$

Nitrogen-doped mesoporous hollow spheres demonstrated high specific surface area and a vegetable sponge-like mesoporous shell with interconnected carbon that facilitated

${ }^{a}$ CAS Key Laboratory of Carbon Materials, Institute of Coal Chemistry, Taiyuan 030001, China. E-mail: zjliu03@sxicc.ac.cn; Fax: +863514084106 ${ }^{b}$ Hebei Normal University for Nationalities, Chengde 067000, China electron transport and Li ion diffusion. They have a capacity of $485 \mathrm{~mA} \mathrm{~h} \mathrm{~g}^{-1}$ at a current density of $500 \mathrm{~mA} \mathrm{~g}^{-1}$ after 1000 cycles. At a higher current density of $4.0 \mathrm{Ag}^{-1}$, these spheres can maintain a rather high capacity of $214 \mathrm{~mA} \mathrm{~h} \mathrm{~g}{ }^{-1} \cdot{ }^{35}$

Chen et $a l .{ }^{36}$ have explored a flexible carbon nanotube electrode for LIBs using multiwalled carbon nanotube-entangled networks integrated into a highly conducting carbon layer. The flexible electrode delivers a significant fully reversible capacity of $572 \mathrm{~mA} \mathrm{~h} \mathrm{~g}{ }^{-1}$, which is higher than the theoretical capacity of graphite $\left(372 \mathrm{~mA} \mathrm{~h} \mathrm{~g}{ }^{-1}\right)$. The good performance of the flexible electrode is ascribed to its novel, three-dimensional porous nanostructure, which provides highly reversible insertion/extraction process of lithium ion onto/from the nanostructured electrode. The special design of the flexible carbon nanotube electrode also provides robustness without

Junzhong Wang ${ }^{32}$ has used natural microcrystalline graphite minerals to produce high quality graphene microsheets through a scalable electrochemical and mechanical exfoliation method. The graphene microsheets exhibit a small sheet size of $0.2-0.6 \mu \mathrm{m}^{2},<5$ atomic layers, few defects, and high purity. The graphene anode has a reversible capacity of $390 \mathrm{~mA} \mathrm{~h} \mathrm{~g}{ }^{-1}$ at a current density of $40 \mathrm{~mA} \mathrm{~g}^{-1}$ after 220 cycles that demonstrates its good cyclability. Notably, it retained a specific capacity of $200 \mathrm{~mA} \mathrm{~h} \mathrm{~g}^{-1}$ at a higher current density of $595 \mathrm{~mA}$ $\mathrm{g}^{-1}$ within $17 \mathrm{~min}$ and can be used for high-rate energy storage.

Although graphite has been commercially applied in LIBs, it cannot meet the growing demand for LIBs with higher energy the use of any binder or substrate for mechanical integrity. 
and power densities. Many researchers have tried their best to find advanced anode materials to substitute graphite. ${ }^{37-42}$ The developed metal oxides, ${ }^{\mathbf{4 3}-47}$ metal sulfides, ${ }^{\mathbf{4 8 , 4 9}}$ and silicon $(\mathrm{Si})^{50-62}$ have higher theoretical capacity than graphite. Among these different types of materials, Si has been proposed as the most promising anode material due to its corresponding high theoretical lithium storage capacity ( $4200 \mathrm{~mA} \mathrm{~h} \mathrm{~g}{ }^{-1}$ for $\mathrm{Li}_{22} \mathrm{Si}_{5}$ ), high volumetric capacity (9876 $\mathrm{mA} \mathrm{h} \mathrm{cm}^{-3}$ ), and low-cost. However, Si generally induces volume expansion (>300\%) during the formation of the $\mathrm{Li}_{x} \mathrm{Si}$ alloy that results in cracking and pulverization, loss of electrical contact, and short cycle life. To overcome the abovementioned limitations, many methods and techniques have been applied to improve the capacity, at various rates, and cycling life of this alloy.

Nanofibers have already been studied as anodes for LIBs. The Si/carbon composite is first spun into nanofibers, which are then coated by reduced graphene oxide. ${ }^{63}$ They show good electrochemical performance with a high reversible capacity of $1055.1 \mathrm{~mA} \mathrm{~h} \mathrm{~g}^{-1}$ after 130 cycles at a current density of $0.1 \mathrm{~A} \mathrm{~g}^{-1}$. At a higher current density of $5 \mathrm{~A} \mathrm{~g}^{-1}$, they demonstrate an outstanding reversible capacity of $358.2 \mathrm{~mA} \mathrm{~h} \mathrm{~g}^{-1}$. This might be ascribed to the sandwich structure, which maintains structural integrity and improves electrochemical conductivity.

To obtain high-performance anode materials, Li et al. have developed face-to-face contact and open-void coinvolved $\mathrm{Si} / \mathrm{C}$ nanohybrids as anode materials using a layer of $\mathrm{Si}$ anchored onto a three-dimensional graphene/carbon nanotube aerogel framework and well-balanced open voids via chemical vapor deposition method. ${ }^{64}$ The prepared nanohybrids stabilize the structure of the electrode, resulting in a high reversible discharge capacity of $1498 \mathrm{~mA} \mathrm{~h} \mathrm{~g}^{-1}$ at the current density of 200 $\mathrm{mA} \mathrm{g}^{-1}$ and excellent rate capability (462 $\mathrm{mA} \mathrm{h} \mathrm{g} \mathrm{g}^{-1}$ at current density of $10 \mathrm{~A} \mathrm{~g}^{-1}$ ). When cycled at a higher current density of $10 \mathrm{~A} \mathrm{~g}^{-1}$, the nanohybrids still demonstrate no obvious capacity decay even after 2000 cycles, thus showing perfect cyclability.

The sandwich-structured graphite-metallic Si@C nanocomposites have been prepared using a ball-milling process and further modified by carbon layers. ${ }^{65}$ As anode materials for LIBs, they improve the electrochemical performance as compared to the pure Si anode. They exhibit a high reversible capacity of $1700 \mathrm{~mA} \mathrm{~h} \mathrm{~g}^{-1}$ after 100 cycles at $0.5 \mathrm{C}$ with only $0.02 \%$ capacity decay per cycle. They also have a good rate capability, with a reversible capacity of 650 and $251.2 \mathrm{~mA} \mathrm{~h} \mathrm{~g}^{-1}$ at 1 and 5C, respectively. The advanced structural design provides a highly conductive network and prevents $\mathrm{Si}$ pulverization during cycling, which improves the electrochemical performance.

Combining graphite and $\mathrm{Si}$ as an integrally bonded anode material for LIBs is a clever technique. ${ }^{66}$ Ko et al. have synthesized Si-nanolayer-embedded graphite for high-energy lithiumion batteries. The prepared hybrids completely overcome the detrimental effects arising from volume variation. This structure supports electrical interconnectivity and morphological integrity for the electrode structure. The hybrids show a high first-cycle coulombic efficiency of $92 \%$ and high capacity retention of $96 \%$ after 100 cycles. With $\mathrm{LiCoO}_{2}$ as a cathode, the full cell delivers a higher energy density $\left(1043 \mathrm{~W} \mathrm{~h} \mathrm{I}^{-1}\right)$ than the current commercial LIBs (900 $\left.\mathrm{W} \mathrm{h} \mathrm{I}^{-1}\right)$.
The strategy of hybridizing Si and carbon and incorporating $\mathrm{Si}$ nanoparticles into void-containing carbon matrices can improve the capacity and cycle life. Taking mass production and production technique into consideration, the involved technology and three-dimensional nanostructure of the electrode are difficult to handle in commercial production. Herein, we demonstrated a hybrid of Si and carbon by simply mixing $\mathrm{Si}$ nanoparticles and carbon materials via a thermal treatment. The pitch-based carbon fibers with excellent electrical/thermal conductivity and low density have been in mass production and applied in many different fields in the market. In the hybrids, self-made carbon fibers were used to enhance the electrical contact between Si and the carbon matrix and thereby the electrical conductivity of the anode. Among them, carbon coating derived from a low-cost carbon source via a thermal treatment was prepared to buffer the volume change, to enhance the integrity of the anode during the charge/discharge processes, and also to minimize direct contact between $\mathrm{Si}$ and the electrolyte. Taking the double protection for Si nanoparticles into consideration, the Si nanoparticle/hollow graphite fiber/carbon coating (SiP/HGF/C) composites were prepared to possibly replace the commercial graphite anode for rechargeable LIBs. In the $\mathrm{SiP} / \mathrm{HGF} / \mathrm{C}$ composites, SiPs had a weight ratio of $35 \%$. The SiPs were the main contributor to the capacity of the electrode due to their superior high theoretical lithium storage capacity.

\section{Experimental}

\subsection{Raw materials}

Si nanoparticles were supplied by Xuzhou Jiechuang New Material Technology Co., Ltd., China. HGFs were made via melt spinning in our laboratory. Low-cost sucrose of $99 \%$ purity was purchased from the market. The softening point of the isotropic pitch was $553 \mathrm{~K}$. The isotropic pitch was separated into toluene soluble (TS, $31.08 \mathrm{wt} \%$ ) and insoluble (TI) fractions. The fraction of TI was separated into quinoline soluble (QS, $46.03 \mathrm{wt} \%$ ) and insoluble fractions (QI, $22.89 \mathrm{wt} \%$ ).

The isotropic pitch was first spun into fibers using a spinnerette under a nitrogen atmosphere. The as-spun fibers were thermo-oxidatively stabilized at $553 \mathrm{~K}$ for $0.5 \mathrm{~h}$ in an oxidation oven. The stabilized fibers were carbonized at $1273 \mathrm{~K}$ for $0.5 \mathrm{~h}$ under a nitrogen atmosphere in a tube furnace. The hollow carbon fibers were finally graphitized at $3073 \mathrm{~K}$ for 20 minutes under an argon atmosphere.

The SiP/HGF composite was prepared by simply mixing the SiPs and HGFs (1: 1 by weight) in ethanol via bath sonication. Then, the mixture was slowly dried in air at room temperature.

The $\mathrm{SiP} / \mathrm{HGF} / \mathrm{C}$ composite was prepared by simply mixing the SiP/HGF composite and sucrose ( $7: 12$ by weight) in deionized water via bath sonication. Then, the mixture was carbonized at $1073 \mathrm{~K}$ for $0.5 \mathrm{~h}$ under a nitrogen atmosphere in a tube furnace.

\subsection{Characterization and electrochemical evaluation}

The crystallite structure of materials was characterized between 10 and $90^{\circ}$ at the scan rate $5^{\circ} \min ^{-1}$ via an X-ray diffraction 
system (XRD; D8 advance, Brucker.) equipped with $\mathrm{Cu} \mathrm{K}_{\alpha}$ radiation. The values of interplanar spacing $\left(d_{002}\right)$ were characterized. Field-emission scanning electron microscopy (SEM, JSM-7001F) and field-emission transmission electron microscopy (TEM, JEM-2100F) were used to observe the microstructure of the samples.

The working electrodes consisted of an active material, acetylene black, and a sodium carboxymethyl cellulose binder in a weight ratio of $7: 2: 1$. CR 2016-type coin cells were assembled in a glovebox under an $\mathrm{Ar}$ atmosphere. A Li foil was used as the counter electrode and reference electrode, with a microporous polypropylene film (Celgard 2400) as the separator. The electrolyte was composed of $1 \mathrm{M} \mathrm{LiPF}_{6}$ in ethylene carbonate-dimethyl carbonate (1:1 by volume) and 5 vol\% vinylene carbonate. The cells were galvanostatically discharged and charged using a battery test system (LAND CT 2001A model, Wuhan Jinnuo Electronics Ltd.) in the voltage range of $0.01-2 \mathrm{~V}$ at room temperature.

\section{Results and discussion}

The microstructure of the samples was observed by SEM. The mean particle size of the Si nanoparticles was about $80 \mathrm{~nm}$, and the purity was 99\%, as shown in Fig. 1a. HGFs were prepared to be reinforced materials, as shown in Fig. 1b. The external diameter of the GHFs was approximately $19.9 \pm 0.6 \mu \mathrm{m}$, and their wall thickness was approximately $5.5 \pm 0.4 \mu \mathrm{m}$. XRD was carried out to further investigate the structure of the samples. Fig. 1c shows typical characteristic peaks assigned to (111), (220), (311), (400), and (422) planes of the crystallized Si nanoparticles. To avoid the shifting and broadening of diffraction profiles, the internal Si standard was used in the XRD analysis. The interplanar spacing of the HGFs was $0.3375 \mathrm{~nm}$, which was indicative of good graphite structure, as shown in Fig. 1d.
Fig. 2a shows a representative TEM image of the Si nanoparticles. The diffraction spots obtained in the entire area demonstrated a good crystalline microstructure. In Fig. 2b, the graphite stripes of the HGFs highlight the diffraction spots obtained in the entire area, which indicated a highly graphitic structure. The ribbons of the graphite grain of the HGFs can be obviously observed in the Fig. 2b, which indicate that the HGFs can exhibit good extent of graphitization and good electric conductivity.

The morphology of the SiP/HGF composite before carbon coating is shown in Fig. 3a. The SiPs dispersed uniformly in the composite and adhered to the surface of the HGFs or dispersed between HGFs. The corresponding elemental mapping of the entire area of Fig. 3a is shown in Fig. 3 b and c. Fig. $3 \mathrm{~b}$ indicates the presence of carbon that originated from the HGFs; Fig. 3c shows the elemental mapping of silicon that originated from the SiPs. The elemental mapping also indicated that the SiPs dispersed well in the composite.

The discharge/charge curve of pure SiPs is shown in Fig. 4. They delivered a first discharge capacity of $3448 \mathrm{~mA} \mathrm{~h} \mathrm{~g}^{-1}$ and a charge capacity of $2994 \mathrm{~mA} \mathrm{~h} \mathrm{~g}^{-1}$ at a current density of 100 $\mathrm{mA} \mathrm{g}^{-1}$. Then, the reversible capacity began to sharply decrease, indicating poor reversibility. After 10 cycles, the reversible capacity was $326.9 \mathrm{~mA} \mathrm{~h} \mathrm{~g}{ }^{-1}$, with the irreversible capacity retention of $90 \%$ corresponding to the initial cycle performance. Due to pulverization and loss of electrical contact between the active material and the current collector, pure SiPs as an anode material show capacity fading and short battery lifetime.

The strategy to solve these issues to improve the electrochemical performance of pure Si should not only enhance the electrical conductivity of the electrode but also buffer the large volume changes to maintain electrode integrity. Carbon materials were designed to promote the electrical conductivity of the
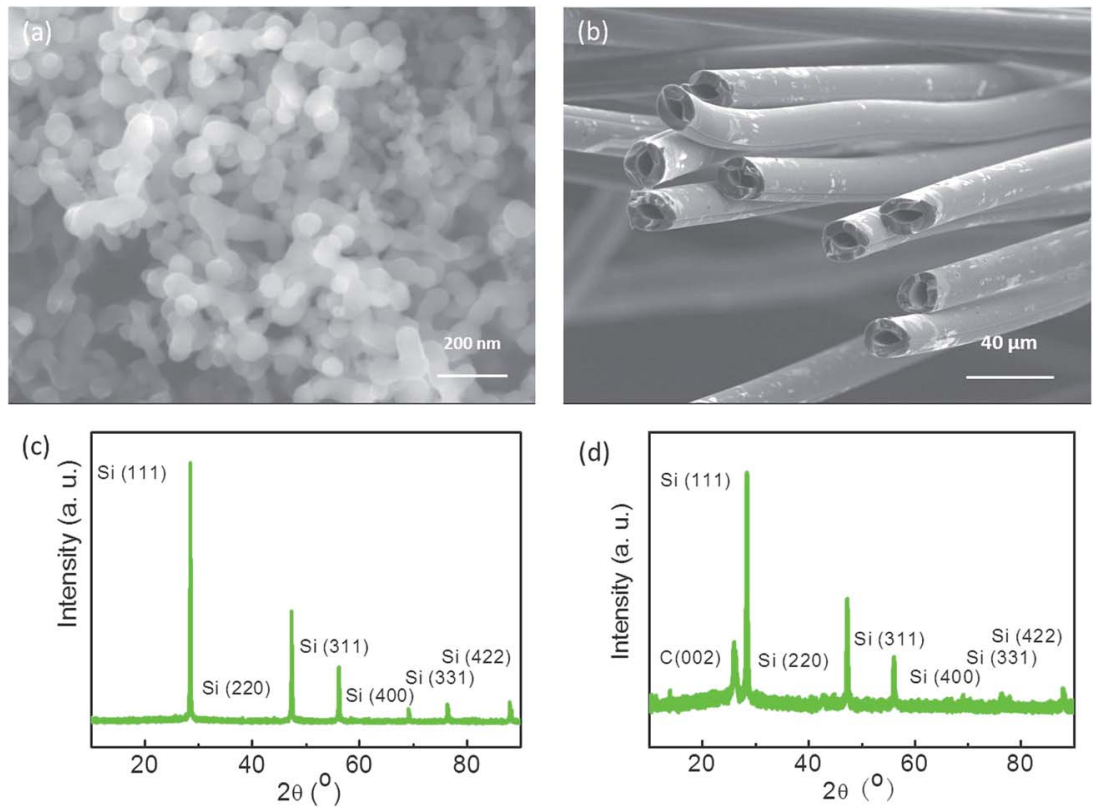

Fig. 1 SEM images of (a) Si nanoparticles and (b) HGFs. X-ray diffraction patterns of (c) Si nanoparticles and (d) HGFs. 

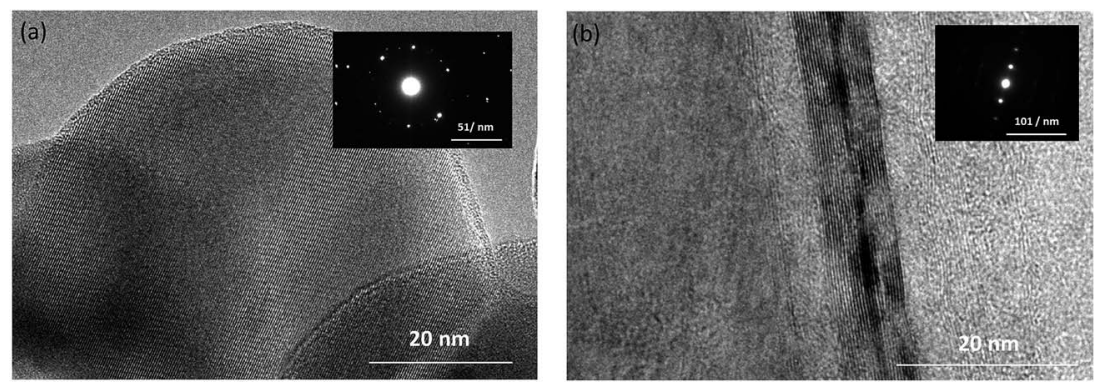

Fig. 2 TEM images with electron diffraction patterns of (a) Si nanoparticles and (b) HGFs.
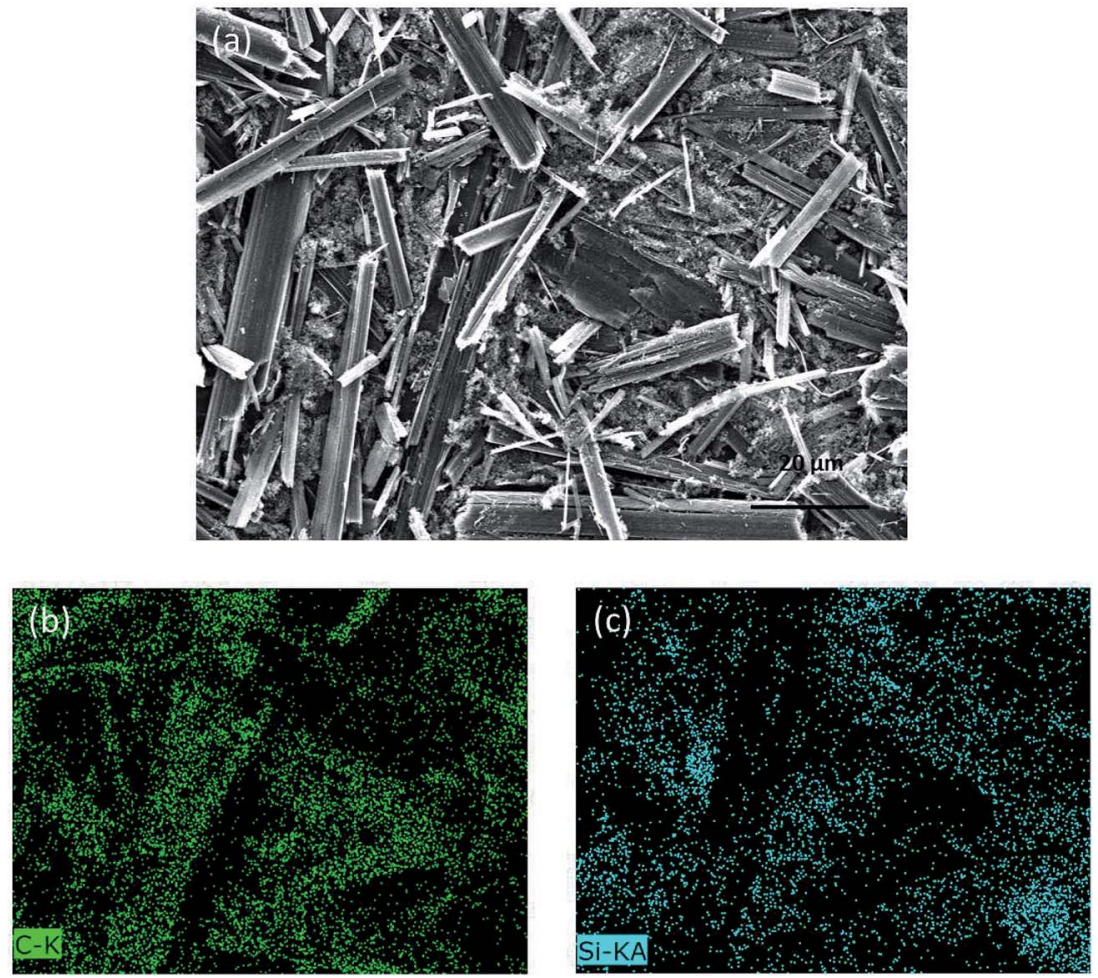

Fig. 3 SEM image with elemental mapping of the (a) SiP/HGF composite, (b) HGFs, and (c) SiPs.

electrode. Graphene has been proven to have unique electrical conductivity due to its special structure and has potential application in electronics as well as energy conversion and storage devices. However, its large surface area results in low

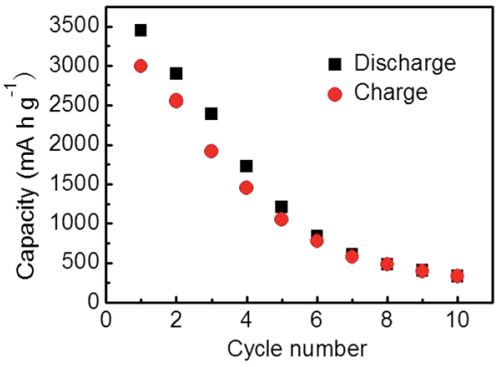

Fig. 4 Cycle performance of the SiPs. initial coulombic efficiency. Moreover, graphene is expensive, which would increase the overall cost of the LIBs. A pitch-based carbon fiber has been recognized as a strategic material due to its high Young's modulus, excellent thermal and electrical conductivity, and low-cost. Self-made HGFs treated at $3073 \mathrm{~K}$ show good graphite characteristics and can store $\mathrm{Li}^{+}$; thus, they can be potential reinforced materials for Si-based LIBs.

Cycle performance of the HGFs and the SiPs/HGFs was verified at a current density of $50 \mathrm{~mA} \mathrm{~g}^{-1}$. As reinforced materials, the HGF electrode delivered an initial discharge and charge capacities of 443.7 and $375.1 \mathrm{~mA} \mathrm{~h} \mathrm{~g}^{-1}$, respectively, with a coulombic efficiency of $84.5 \%$ (Fig. $5 \mathrm{a}$ )..$^{15,67}$ The first 10 curves of discharge and charge overlapped quite well, indicating good cycling stability. After 50 cycles, the electrode's reversible capacity is maintained at $338.9 \mathrm{~mA} \mathrm{~h} \mathrm{~g}^{-1}$ with steady coulombic efficiency (Fig. 5c). 


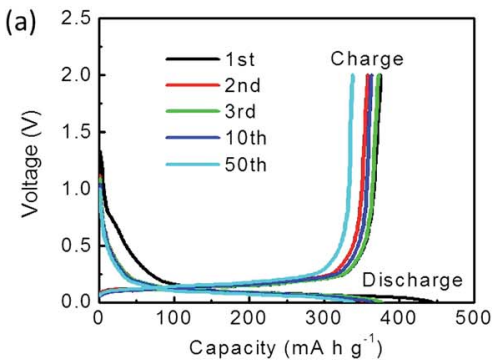

(c)

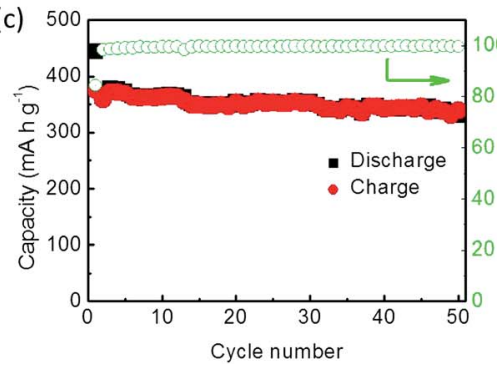

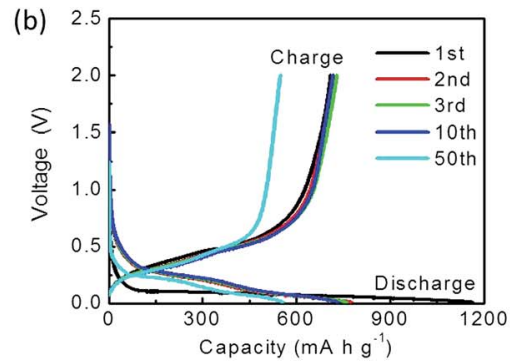

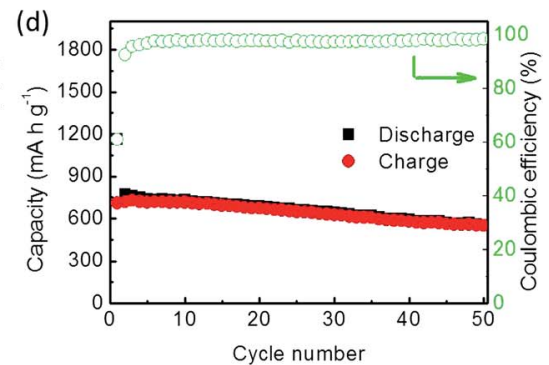

Fig. 5 Voltage profiles of (a) HGFs and (b) SiP/HGF. Cycle performance of (c) HGFs and (d) SiP/HGF.

The SiP/HGF composite exhibited a first discharge capacity of $1164.4 \mathrm{~mA} \mathrm{~h} \mathrm{~g}^{-1}$ and a first charge capacity of $709.8 \mathrm{~mA} \mathrm{~h} \mathrm{~g}^{-1}$, with a coulombic efficiency $61 \%$ (Fig. 5b). The loading density of the active material containing SiPs and HGFs was $\sim 2.2 \mathrm{mg}$ $\mathrm{cm}^{-2}$. Then, the reversible capacity began to decrease, and a discharge capacity of $556.2 \mathrm{~mA} \mathrm{~h} \mathrm{~g}^{-1}$ and a charge capacity of $548.6 \mathrm{~mA} \mathrm{~h} \mathrm{~g}{ }^{-1}$ were maintained after 50 cycles, which also prolonged the lifetime of the pure SiPs. The abovementioned results revealed that the SiP/HGF anode had a better cyclability with high reversible capacity than the pure SiP anode. This also indicates that the HGFs not only store/release Li ion, but also improve the lifetime of the anode.

Although the HGFs improved the electrical contact between the SiPs and current collector, the capacity still decreased. This was attributed to the large volume changes of the SiPs. Therefore, a more protective strategy to improve the electrochemical performance of the SiP anode should be developed. An efficient and inexpensive method to buffer the volume changes of SiPs is to use a carbon coating for the SiP/HGF composite.

The cycle performance of the carbon fibers was tested at a current density of $50 \mathrm{~mA} \mathrm{~g}^{-1}$. Their initial discharge and charge capacities were 371.4 and $205.3 \mathrm{~mA} \mathrm{~h} \mathrm{~g}^{-1}$, respectively, with a coulombic efficiency of $55.2 \%$ (Fig. 6a). After 50 cycles, the reversible capacity was $188.7 \mathrm{~mA} \mathrm{~h} \mathrm{~g}{ }^{-1}$, which was lower than that of the graphitized fibers. This also indicated that the graphitized fibers were superior to be used as anode materials in the composites than the carbon fibers (Fig. 6b).

After further protection, TEM was employed to observe the microstructure of the $\mathrm{SiP} / \mathrm{HGF} / \mathrm{C}$ composite. The circular nanoparticles were $\mathrm{Si}$ nanoparticles coated with carbon, as displayed in Fig. 7. The corresponding parts are marked in this figure.

The cycle performance of the SiP/HGF/C composite was tested at a current density of $50 \mathrm{~mA} \mathrm{~g}{ }^{-1}$. The loading density of the active material containing SiPs, HGFs, and C composite was $\sim 2.4 \mathrm{mg} \mathrm{cm}^{-2}$. Its initial discharge and charge capacities were 1327.2 and $936.6 \mathrm{~mA} \mathrm{~h} \mathrm{~g}^{-1}$, respectively, with a coulombic efficiency of $70.6 \%$ (Fig. 8a). The second and third charge capacities were 947.8 and $987.2 \mathrm{~mA} \mathrm{~h} \mathrm{~g}^{-1}$, respectively. After 10 cycles, the reversible capacity was $1045.2 \mathrm{~mA} \mathrm{~h} \mathrm{~g}^{-1}$, which was $11 \%$ higher than the initial capacity. The first several curves of discharge and charge overlapped quite well, which indicated good cycling stability of the SiP/HGF/C composite anode. After the first cycle, the charge capacity began to steadily increase to $1122.7 \mathrm{~mA} \mathrm{~h} \mathrm{~g}^{-1}$ until the thirty-first cycle (Fig. 8c). This might be attributed to the protection provided by the carbon coating,
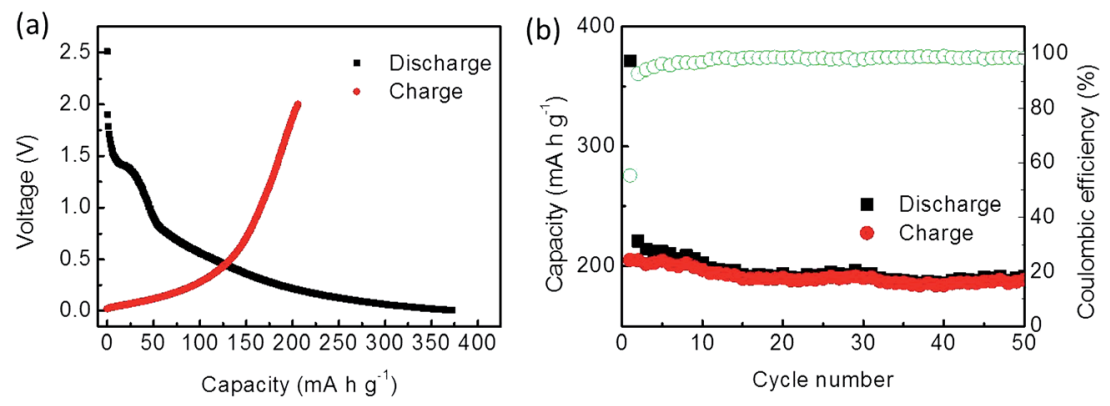

Fig. 6 Electrochemical performance of the carbon fibers: (a) charge/discharge curves of the initial cycle and (b) cycling performance. 


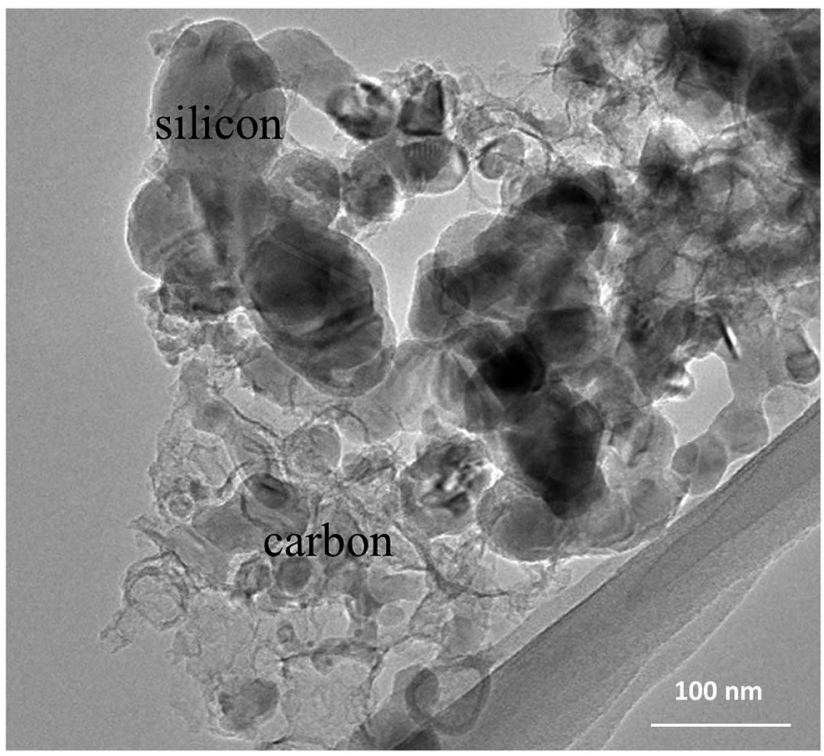

Fig. 7 TEM image of the SiP/HGF/C composite.

which effectively buffered the volume changes and enhanced the electrode intensity during discharge-charge cycles. After this, its reversible capacity was maintained at $910.1 \mathrm{~mA} \mathrm{~h} \mathrm{~g}^{-1}$ at the 50th cycle, which was higher than that of the SiP/HGF composite.

Rate capability is an important factor for using LIBs in energy storage. The rates for the samples were increased stepwise from $50 \mathrm{~mA} \mathrm{~g}^{-1}$ to $800 \mathrm{~mA} \mathrm{~g}^{-1}$ and then switched back. The HGFs reached a reversible capacity of 350.4, 300.3, and 232.7 $\mathrm{mA} \mathrm{h} \mathrm{g}^{-1}$ after 5,10 , and 15 cycles, respectively. At the densities of 400 and $800 \mathrm{~mA} \mathrm{~g}^{-1}$, the HGFs obtained the reversible capacities of 137.9 and $49.7 \mathrm{~mA} \mathrm{~h} \mathrm{~g}^{-1}$, respectively (Fig. 8b).
After the high rate measurements, the HGF electrode tested at $50 \mathrm{~mA} \mathrm{~g}^{-1}$ achieved a reversible capacity of $345.2 \mathrm{~mA} \mathrm{~h} \mathrm{~g}^{-1}$, which was in accordance with the value of the 5th cycle. The good rate capability of this electrode could be helpful for the $\mathrm{SiP} / \mathrm{HGF} / \mathrm{C}$ composite.

The SiP/HGF/C composite delivered the reversible capacities of 1224.6, 1049.1, 679.4, 379.4, and $326.9 \mathrm{~mA} \mathrm{~h} \mathrm{~g}^{-1}$ after 5, 10, 15,20 , and 25 cycles, respectively. At the density of $1000 \mathrm{~mA} \mathrm{~h}$ $\mathrm{g}^{-1}$, the SiP/HGF/C composite obtained a reversible capacity of $284.7 \mathrm{~mA} \mathrm{~h} \mathrm{~g}^{-1}$. After the high rate measurements, the SiP/HGF/ $\mathrm{C}$ composite electrode tested at $50 \mathrm{~mA} \mathrm{~g}^{-1}$ achieved a reversible capacity of $1170.4 \mathrm{~mA} \mathrm{~h} \mathrm{~g}^{-1}$, which was close to the value of the 5th cycle (1224.6 $\mathrm{mA} \mathrm{h} \mathrm{g}^{-1}$ ) (Fig. 8d). The carbon coating could improve the integrity of the electrode, which was helpful for its good rate capability.

The electrical conductivity of the samples was verified via electrochemical impedance spectroscopy (EIS) measurements, as shown in Fig. 9a. The EIS spectra consisted of two semicircles and a straight sloping line. The first semicircle in the high frequency region may have resulted from the formation of SEI, possibly attributed to their large specific surface area mainly due to an external surface. The second semicircle in the medium frequency region probably resulted because of interfacial charge transfer impedance. The straight sloping line in low frequency region was mainly related to lithium diffusion impedance. The straight diffusion tail suggested that the carbon conductive network facilitated the diffusion and transport of lithium ions between the electrode and the electrolyte and thus reduced lithium ion diffusion resistance. The equivalent circuit is shown in Fig. 9c. $R_{\mathrm{e}}$ is the electrolyte resistance and $R_{\text {ct }}$ is the charge transfer resistance. $Q$ is the double-layer constant phase angle element and $Z_{\mathrm{w}}$ is the Warburg impedance related to the diffusion of lithium ions into the bulk of the composite electrode. $C$ is the capacitance, and $R_{\mathrm{f}}$ is the
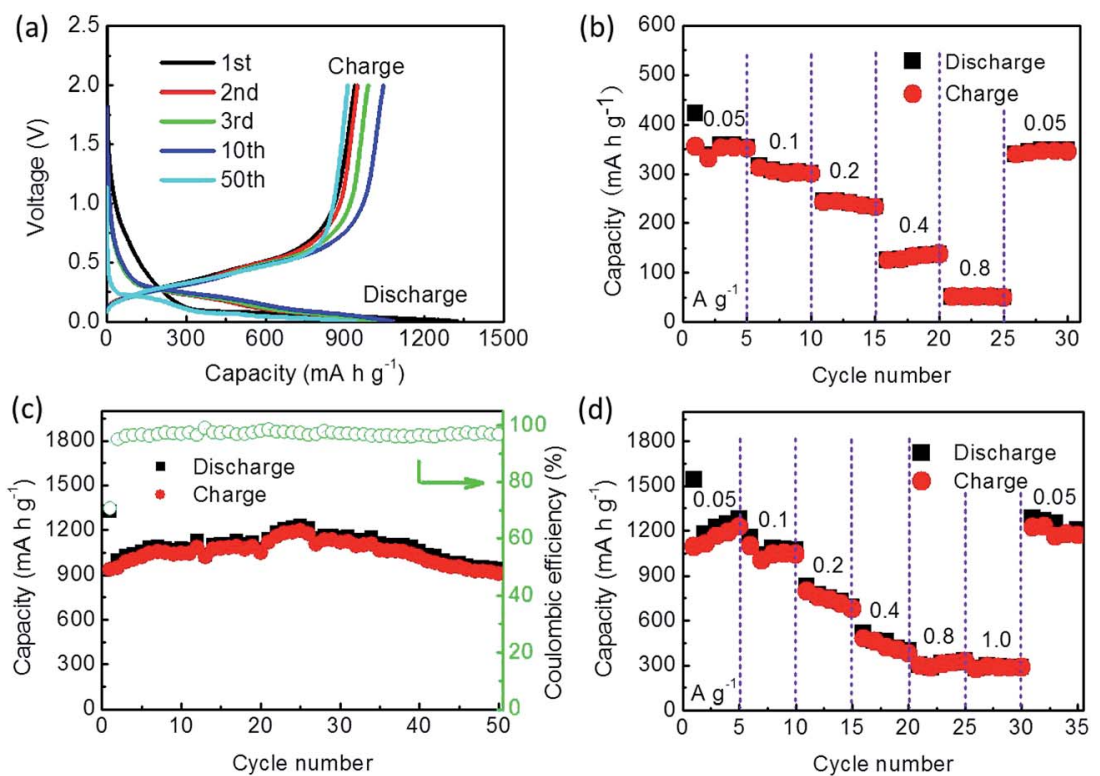

Fig. 8 (a) Voltage profiles of the SiP/HGF/C composite. (b) Rate capability of the HGFs. (c) Cycle performance of the SiP/HGF/C composite. (d) Rate capability of the SiP/HGF/C composite. 

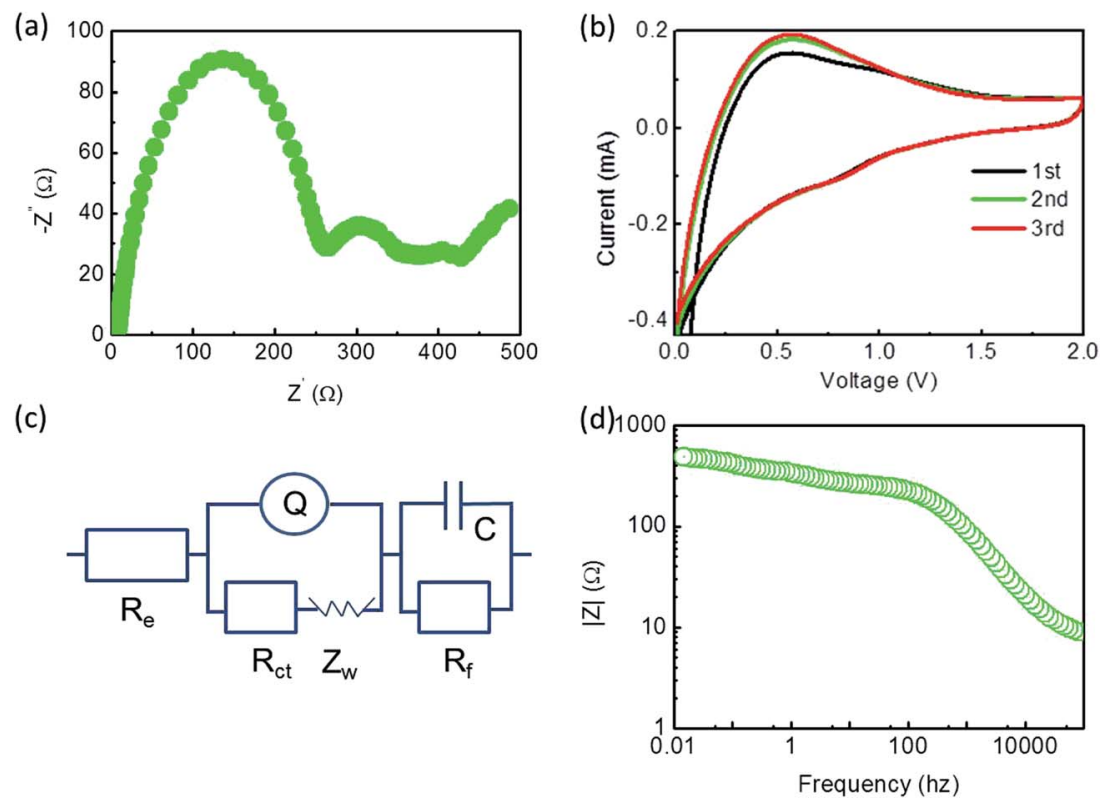

Fig. 9 (a) Nyquist plots of the electrodes of the SiP/HGF/C composite, (b) cyclic voltammetry curves of SiP/HGF/C, (c) equivalent circuit of (a), and (d) relationship between impedance and frequency.

resistance of the surface film and contact. The values of $R_{\mathrm{ct}}$ and $R_{\mathrm{f}}$ for the SiP/HGF/C electrode were 262.7 and $10.7 \Omega$, respectively. The corresponding relationship between impedance and frequency is displayed in Fig. 9d.

A typical cyclic voltammetry (CV) measurement of the electrodes in the voltage range of $0.01-2.0 \mathrm{~V}$ at a sweep rate of $1 \mathrm{mV}$ $\mathrm{s}^{-1}$ is shown in Fig. 9b. In the case of the SiP/HGF/C electrode, upon discharge, the current peak appeared at about $0.56 \mathrm{~V}$. In the following anodic scan, the oxidation peaks were nearly consistent with those of the first scan. During the electrode's first cathodic half-cycle, a peak could be clearly seen at about $0.85 \mathrm{~V}$, which could be attributed to the formation of the SEI film that resulted in an initial irreversible capacity ${ }^{68,69}$ During the following anodic scan, the corresponding anodic peaks had no obvious shift as compared to those of the first scan. The second and third cathodic-anodic scan curves overlapped quite well, this suggested good cycling performance of the electrode.

\section{Conclusions}

In conclusion, the double strategy to modify the cycling performance of pure SiPs was applied. The HGFs with a good graphite structure could improve the electrical conductivity of the electrode. The SiP/HGF composite maintained a discharge capacity of $556.2 \mathrm{~mA} \mathrm{~h} \mathrm{~g}^{-1}$ and a charge capacity of $548.6 \mathrm{~mA} \mathrm{~h}$ $\mathrm{g}^{-1}$ after 50 cycles at the current density of $50 \mathrm{~mA} \mathrm{~g}^{-1}$, which obviously prolonged the lifetime of the pure SiPs. Carbon coating was employed to minimize the direct contact between the SiPs and the electrolyte and buffer the volume changes during cycling. The cycle performance of the SiP/HGF/C composite was tested at a current density of $50 \mathrm{~mA} \mathrm{~g}^{-1}$. Its initial discharge and charge capacities were 1327.2 and 936.6

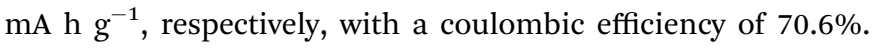

After the first cycle, the charge capacity began to steadily increase to $1122.7 \mathrm{~mA} \mathrm{~h} \mathrm{~g}^{-1}$ until the thirty-first cycle. After this, its reversible capacity maintained at $910.1 \mathrm{~mA} \mathrm{~h} \mathrm{~g}^{-1}$ at 50 th cycle with steady coulombic efficiency. This was attributed to the protection provided by the carbon coating and the addition of the HGFs, which effectively buffered the volume changes, enhanced the intensity of electrode, and improved the electrical conductivity during discharge-charge cycles; this resulted in high reversible capacity, good cycling stability, and good rate capability as compared to those of the pure SiP anode. The SiP/ HGF/C composites are a promising choice to prepare a low-cost anode material for the LIBs.

\section{Acknowledgements}

This work was supported by the Project of Scientific Technological Research and Development Plan of Chengde (201608B004, 20155006), the Science and Technological Research Project for University of Hebei Province (ZD2017310), the Hebei Normal University for Nationalities Foundation for Youths (QN201505), and the National Science and Technological Support Project (2015BAH43F00).

\section{References}

1 J. M. Tarascon and M. Armand, Nature, 2001, 414, 359-367. 2 M. Armand and J. M. Tarascon, Nature, 2008, 451, 652-657.

3 P. G. Bruce, B. Scrosati and J. M. Tarascon, Angew. Chem., Int. Ed., 2008, 47, 2930-2946.

4 Y. P. Wu, E. Rahm and R. Holze, J. Power Sources, 2003, 114, 228-236.

5 S. Xin, Y. G. Guo and L. J. Wan, Acc. Chem. Res., 2012, 45, 1759-1769. 
6 H. Y. Lee, J. K. Baek, S. M. Lee, H. K. Park, K. Y. Lee and M. H. Kim, J. Power Sources, 2004, 128, 61-66.

7 D. Goers, M. E. Spahr, A. Leone, W. Märkle and P. Novák, Electrochim. Acta, 2011, 56, 3799-3808.

8 H. Abe, K. Zaghib, K. Tatsumi and S. Higuchi, J. Power Sources, 1995, 54, 236-239.

9 A. Emori, A. Kudou and T. Horiba, Carbon, 2007, 45, 28572858.

10 W. Guo, X. Li, J. Xu, H. K. Liu, J. Ma and S. X. Dou, Electrochim. Acta, 2016, 188, 414-420.

11 J. K. Lee, K. W. An, J. B. Ju, B. W. Cho, W. I. Cho, D. Park and K. S. Yun, Carbon, 2001, 39, 1299-1305.

12 S.-H. Yoon, C.-W. Park, H. Yang, Y. Korai, I. Mochida, R. T. K. Baker and N. M. Rodriguez, Carbon, 2004, 42, 21-32.

13 V. Subramanian, H. Zhu and B. Wei, J. Phys. Chem. B, 2006, 110, 7178-7183.

14 I. Cameán, A. B. García, I. Suelves, J. L. Pinilla, M. J. Lázaro and R. Moliner, J. Power Sources, 2012, 198, 303-307.

15 L. Wang, Z. Liu, Q. Guo, G. Wang, J. Yang, P. Li, X. Wang and L. Liu, Electrochim. Acta, 2016, 199, 204-209.

16 S. Zhong, J. Hu, Z. Wu and W. Mei, Carbon, 2015, 81, 852.

17 J. Chen, Y. Liu, A. I. Minett, C. Lynam, J. Wang and G. G. Wallace, Chem. Mater., 2007, 19, 3595-3597.

18 C. Zhong, J. Z. Wang, D. Wexler and H. K. Liu, Carbon, 2014, 66, 637-645.

19 A. P. Cohn, L. Oakes, R. Carter, S. Chatterjee, A. S. Westover, K. Share and C. L. Pint, Nanoscale, 2014, 6, 4669-4675.

20 Y. Zhang, W. Bai, J. Ren, W. Weng, H. Lin, Z. Zhang and H. Peng, J. Mater. Chem. A, 2014, 2, 11054-11059.

21 J. Mun, J. H. Park, W. Choi, A. Benayad, J. H. Park, J. M. Lee, S. G. Doo and S. M. Oh, J. Mater. Chem. A, 2014, 2, 1967019677.

22 J. W. Hu, Z. P. Wu, S. W. Zhong, W. B. Zhang, S. Suresh, A. Mehta and N. Koratkar, Carbon, 2015, 87, 292-298.

23 R. Paul, V. Etacheri, V. G. Pol, J. Hu and T. S. Fisher, RSC Adv., 2016, 6, 79734-79744.

24 R. Raccichini, A. Varzi, V. S. K. Chakravadhanula, C. Kübel and S. Passerini, Sci. Rep., 2016, 6, 23585.

25 J. Qin, C. He, N. Zhao, Z. Wang, C. Shi, E. Z. Liu and J. Li, ACS Nano, 2014, 8, 1728-1738.

26 Y. Chen, J. Zhu, B. Qu, B. Lu and Z. Xu, Nano Energy, 2014, 3, 88-94.

27 G. Kucinskis, G. Bajars and J. Kleperis, J. Power Sources, 2013, 240, 66-79.

28 H. Yu, G. Guo, L. Ji, H. Li, D. Yang, J. Hu and A. Dong, Nano Res., 2016, 9, 3757-3771.

29 H. Yu, G. Guo, L. Ji, H. Li, D. Yang, J. Hu and A. Dong, Nano Res., 2016, 9, 1-15.

30 R. Mo, Y. Du, D. Rooney, G. Ding and K. Sun, Sci. Rep., 2016, 6, 19843.

31 L. Jiao, T. Wu, H. Li, F. Li and L. Niu, Chem. Commun., 2015, 51, 15979-15981.

32 J. Wang, J. Huang, R. Yan, F. Wang, W. Cheng, Q. Guo and J. Wang, J. Mater. Chem. A, 2015, 3, 3144-3150.

33 L. Zhan, S. Yang, Y. Wang, Y. Wang, L. Ling and X. Feng, Adv. Mater. Interfaces, 2014, 1, 274-276.
34 M. Yoshio, H. Wang and K. Fukuda, Angew. Chem., Int. Ed., 2003, 42, 4203-4206.

35 K. Huo, W. An, J. Fu, B. Gao, L. Wang, X. Peng, G. J. Cheng and P. K. Chu, J. Power Sources, 2016, 324, 233-238.

36 J. Chen, A. I. Minett, Y. Liu, C. Lynam, P. Sherrell, C. Wang and G. G. Wallace, Adv. Mater., 2008, 20, 566-570.

37 U. Kasavajjula, C. Wang and A. J. Appleby, J. Power Sources, 2007, 163, 1003-1039.

38 W. Zhang, J. Power Sources, 2011, 196, 13-24.

39 X. W. Zhang, P. K. Patil, C. Wang, A. J. Appleby, F. E. Little and D. L. Cocke, J. Power Sources, 2004, 125, 206-213.

40 Y. Liu, W. Zhang, Y. Zhu, Y. Luo, Y. Xu, A. Brown, J. N. Culver, C. A. Lundgren, K. Xu, Y. Wang and C. Wang, Nano Lett., 2012, 13, 293-300.

41 A. S. Arico, P. Bruce, B. Scrosati, J. M. Tarascon and W. van Schalkwijk, Nat. Mater., 2005, 4, 366-377.

42 Y. M. Chiang, Science, 2010, 330, 1485-1486.

43 S. K. Park, C. Y. Seong, S. Yoo and Y. Piao, Energy, 2016, 99, 266-273.

44 D. Wang, H. He, L. Han, R. Lin, J. Wang, Z. Wu, H. Liu and H. L. Xin, Nano Energy, 2016, 20, 212-220.

45 J. Yue, X. Gu, L. Chen, N. Wang, X. Jiang, H. Xu, J. Yang and Y. Qian, J. Mater. Chem. A, 2014, 2, 17421-17426.

46 W. Zhang and D. Liu, Electrochim. Acta, 2015, 156, 53-59.

47 M. Y. Son, J. H. Kim and Y. C. Kang, Electrochim. Acta, 2014, 116, 44-50.

48 X. Xu, W. Liu, Y. Kim and J. Cho, Nano Today, 2014, 9, 604630.

49 L. Fei, B. P. Williams, S. H. Yoo, J. M. Carlin and Y. L. Joo, Chem. Commun., 2016, 52, 1501-1504.

50 B. Wang, X. Li, B. Luo, X. Zhang, Y. Shang, A. Cao and L. Zhi, ACS Appl. Mater. Interfaces, 2013, 5, 6467-6472.

51 L. Xue, G. Xu, Y. Li, S. Li, K. Fu, Q. Shi and X. Zhang, ACS Appl. Mater. Interfaces, 2012, 5, 21-25.

52 X. H. Liu, L. Zhong, S. Huang, S. X. Mao, T. Zhu and J. Y. Huang, ACS Nano, 2012, 6, 1522-1531.

53 B. Wang, X. Li, X. Zhang, B. Luo, M. Jin, M. Liang, S. A. Dayeh, S. T. Picraux and L. Zhi, ACS Nano, 2013, 7, 1437-1445.

54 H. Li, C. Lu and B. Zhang, Electrochim. Acta, 2014, 120, 96101.

55 B. S. Lee, S. B. Son, K. M. Park, J. H. Seo, S. H. Lee, I. S. Choi, K. H. Oh and W. R. Yu, J. Power Sources, 2012, 206, 267-273.

56 B. Liu, X. Wang, H. Chen, Z. Wang, D. Chen, Y. B. Cheng, C. Zhou and G. Shen, Sci. Rep., 2013, 3, 1622.

57 A. M. Chockla, J. T. Harris, V. A. Akhavan, T. D. Bogart, V. C. Holmberg, C. Steinhagen, C. B. Mullins, K. J. Stevenson and B. A. Korgel, J. Am. Chem. Soc., 2011, 133, 20914-20921.

58 L.-F. Cui, Y. Yang, C.-M. Hsu and Y. Cui, Nano Lett., 2009, 9, 3370-3374.

59 T. H. Hwang, Y. M. Lee, B.-S. Kong, J.-S. Seo and J. W. Choi, Nano Lett., 2012, 12, 802-807.

60 N. Liu, Z. Lu, J. Zhao, M. T. McDowell, H. W. Lee, W. Zhao and Y. Cui, Nat. Nanotechnol., 2014, 9, 187-192.

61 L. Wang, Q. Guo, J. Wang, H. Li, G. Wang, J. Yang, Y. Song, Y. Qin and L. Liu, RSC Adv., 2014, 4, 40812-40815. 
62 X. Dong, C. Lu, L. Wang, P. Zhou, D. Li, L. Wang, G. Wu and Y. Li, RSC Adv., 2016, 6, 12737-12743.

63 Y. Chen, Y. Hu, Z. Shen, R. Chen, X. He, X. Zhang, Y. Zhang and K. Wu, Electrochim. Acta, 2016, 210, 53-60.

64 S. Jing, H. Jiang, Y. Hu, J. Shen and C. Li, Adv. Funct. Mater., 2015, 25, 5395-5401.

65 Z. Sun, G. Wang, T. Cai, H. Ying and W. Han, Electrochim. Acta, 2016, 191, 299-306.
66 M. Ko, S. Chae, J. Ma, N. Kim, H. W. Lee, Y. Cui and J. Cho, Nat. Energy, 2016, 1, 16113.

67 Y.-P. Wu, C. R. Wan, C. Y. Jiang, S. B. Fang and Y. Y. Jiang, Carbon, 1999, 37, 1901-1908.

68 H. W. Ping Liu, J. Power Sources, 1995, 56, 81.

69 J. Graetz, C. C. Ahn, R. Yazami and B. Fultz, Electrochem. Solid-State Lett., 2003, 6, A194. 